\title{
Hate Speech: A Linguistic Analysis of Student Messages in Schools
}

\author{
Sofia Tsagdi*, Kostas Theologou \\ National Technical University of Athens, Greece.
}

How to cite this paper: Sofia Tsagdi, Kostas Theologou. (2021). Hate Speech: A Linguistic Analysis of Student Messages in Schools. The Educational Review, USA, 5(4), 98-105.

DOI: 10.26855/er.2021.04.003

Received: March 15, 2021

Accepted: April 12, 2021

Published: April 26, 2021

Corresponding author: Sofia Tsagdi, National Technical University of Athens, Greece.

Email: stsagdi@gmail.com

\begin{abstract}
Analysis of student messages is often marginalized in educational research and has not been employed to collect information about the messages in a school and their effect on students. The aim of this paper is to use visual methods to collect student messages around the school premises and then analyze them, in order to understand how these images/messages are perceived and processed by high school students in Greece. It reports on a participative research project in 9 secondary schools in Greece from distinctively different cultural and economic backgrounds. This paper draws on content analysis as a systematic, rigorous approach to analyzing documents obtained or generated in the course of research. The paper will highlight, how student messages can reveal the social and cultural influences within a school. Also, the paper seeks to confront the problem of identifying and censoring hateful messages around the school while weighting the right to freedom of speech.
\end{abstract}

\section{Keywords}

Hate Speech, Schools, Student Messages, School Culture

\section{Introduction}

In the last decades, there has been an increasing move towards improving public education in Greece. Several institutional changes in National exams were implemented, new books were written etc. However, all these changes were technical and their aim was targeted on how to improve and promote academic excellence. The changes concentrated more on educational content and ignored the human-resource perspective. Moreover, they were applied in all schools ignoring the complexity of the life of students in the school units, their needs and how they interact. Linearity and equal opportunities were overemphasized, rather than paying sufficient attention to the characteristics of students' population and either support or subvert them. We believe that by focusing on student needs and their voice we can solve many of the serious problems in schools that seek immediate action. At this point we feel we should make clear where we part form many other commentators on the issue of Greek school problems. We want to draw emphasizes from the outset of our article, that blaming the teachers and students as well as castigating schools is a practice we do not need anymore. Such features of educational policy in Greece of the last decades belong to the past and have demonstrably failed. We believe, we must avoid mistakes of the past and encourage sincere fundamental changes that are carefully constructed and not just smokescreen rapid ones, as were many of the changes in the past years.

In this respect, our paper sets out to investigate one of the most challenging issues in Education in recent years (Flutter \& Rudduck, 2004): student's voice. This need has resulted partly from the observation of the frame- work constitutional changes, and partly from studying an increasing number of educators and researchers who describe the benefits of consulting children and young teenagers on issues that directly and indirectly affect them in their school or college life (Mascolo, 2009). In the same vein, the United Nations Convention on the Rights of the Child (1989; UN General As- 
sembly Resolution 44/25) proclaim the importance of the children right to express their views, to be heard and to take part in decisions that affect them. In addition, the 2002 Education Act put forward the need of schools to consult with students and receive feedback from them (Netscafe, 2005). Student voice also has an explicit place in recent educational policies of several countries promoting personalized learning. In the same note, it has been long argued that by studying students' voice the implicit powerful forces that shape the social space in schools can be unraveled (Lewin, Lippitt, \& White, 1939; Argyris, 1958). By understanding and bringing together the experiences, beliefs, attitudes, ideology of student population one can make visible the unseen, unquestioned, unconscious curriculum and culture of a school (Mortimore, 1979; Hill, 2006). Thus, many problems within school units can be identified and sourced, students performance can be enhanced. Under the auspices of the Educational Act 2002 and NCLB 2005 (No Child Left Behind), emphasis on performance and student satisfaction with school services has frequently been used as vital performance information. A strong relationship between student satisfaction and student performance has been often put forward (Jenkins, 2006). The main objective of our article is to foreground, through the study of the language of the informal messages students put around the school, the way students' convey and construct aspects of their social identity and the social relationships constructed within the school community and thus find their voice in the school (Holmes, 2017). As Halliday (2006, p. 19) has argued "text is an instance of social meaning in a particular content situation" in this respect by analyzing students messages we can claim being able to identify and see the social, cultural characteristics and values of each school population (Jewitt, 2001). In other words, by reading their messages, we can meet the need to explore from the standpoint or 'positional lenses' (Smyth, 2006) the existential experiences of young people, their interests and their identity and from there to pursue forms of school organization, culture and leadership that acknowledge those important realities. This involves sustaining a working hypothesis on how students see themselves and the qualities they attribute to themselves, and the social and school identities made available to them. In this sense, many young people are experiencing multiple realities-living in one reality at home, in another reality with peers, and then trying to find another reality-identity at school (Lodge, 2005). Many young people negotiate their school lives through consciously taking on different identities in these different contexts (Bragg, 2007). Thus, through our study we aim to fill this gap and find the students' voice and notion of a "good student" and "attitudes to school life" through their own writings. We try to identify the students' frames of reference through their own expressions.

For the purposes of this study, we will focus on student messages found mainly in non- teaching spaces. It has been found that everyday thoughts can be manifested visually in the built environment (Burke \& Grosvenor, 2003). Thus, nonteaching spaces make an important contribution to identifying student's thoughts. Many of us retain a strong normative visual recollection of school diners, corridors, playgrounds and adventurous in remote corners of them. Non-teaching spaces are also important because they are less formal than the actual board or the formal messages placed by teachers and are rarely the center of attention (Emisson, 2000; Prosser, 2007). Consequently, we feel that drawing messages from places where the students feel safer and out of the spotlight will provide us with more objective insight of their thoughts and feelings.

In this paper, we focus on the Greek context, where student voice is only allowed to be heard in students' board meeting with the principal of each school. The evaluation is directed only from teacher to students and the opinions of students are usually pinned to informal oral discussions. In this paper, we try to underscore the necessity to bridge students' views and voice with formal teaching and curriculum. An effort is made to answer the intriguing question of "what students actually think" when in school; and through that provide a crucial first step in understanding and finding students' values and social identity in different school units. When students feel that their lives, experiences, cultures, and aspirations are valued, not trivialized, or denigrated, they develop a positive attitude towards the institution of schooling (Fielding, 2004). They feel that schooling is simply worth their serious involvement, in schools that bring into existence authentic forms of student voice. Based on this evidence we feel that by identifying and specifying student voice in schools we will have make a first step in that direction. Educational research on visual images/student images of schools is scarce particularly in our context. There are no studies that focus on students' messages and visual culture. Educators often either ignore and overlook school visual culture, or in most cases educators, as well as those in authority, make decisions on what should be placed or allowed in a school under the perception that high school students are incapable of having opinion on the issue. The educators tend to feel that students do not have firmly formed views (James et al., 1998), or need to be protected from the perhaps sensitive/threatening issues (Cook, 2014; Cremin \& Slatter, 2004). Our paper wishes to fill this gap in research and the way school images affect students of particular school units (Kalatzis \& Cope, 2008). The central objective of this article is not only to understand students view through their messages but also as act as a stimulator to further research in the future. The article is structured as follows: First we outline the method of our study and the way we gathered and processed our findings. Then discuss in detail the key findings in the student messages. We also discuss and highlight the relationship between students' messages and school 
culture. Finally, we go on to discussing the alarming percentage of hate speech we noticed in student messages. The paper concludes by highlighting the problems, hurdles of our field research and by suggesting issues that need to be further addressed.

\section{Method}

The procedure followed was: First, we applied and received approval of our research project from the National Technical University's Ethics Committee. Then, we filed the necessary papers to the Ministry of Education to ensure access to the schools and their collaboration to research. This process took about 3 months to be completed. Afterwards, we contacted the principals of the schools to arrange a convenient date to visit the school and take pictures and video of the images in and outside school premises. Then, in the arranged date we took photos of the school, in one day after school hours, in order not to interrupt school life but also so as not to have issues of shooting students while trying to capture an image. This made the research logistically possible while offering a discrete moment of school life to analyze.

The population of our research consists of all the public secondary schools of the region of Attica. According to the Ministry of Internal Affairs, there are 406 secondary schools in Attica district. Moreover, the number of the respective type of schools that exist in Greece is 1,661. Therefore, the population under research is greater than the $24 \%$ of the respective population in throughout Greece. In terms of student population, the entire population of secondary school students is 296.776, whereas in the 406 secondary schools of Attica prefecture there are 96.626 students.

The selection of this population has been made for various reasons. First of all, almost $1 / 3$ of the secondary school students of the Greece attend one of the secondary schools of district of Attica and thus the generalization of the results will be facilitated. Moreover, time schedule restrictions as well as budget limitations for the completion of the current study have been taken into account, especially if we bear in mind that the integration of provincial secondary schools would require plenty of resources. Also the approval for research provided by the relevant authority (Ministry of Education) includes only a limited number of schools, in order to minimize the interference with the primary educational activities.

\section{Sample}

The sample consists of 9 secondary schools $(\mathrm{N}=9)$, which accounts for the $2.2 \%$ of the entire research population. The 9 secondary schools have been chosen such that the majority of the students (>85\%) possess Greek citizenship, in order to restrict the effect of variables pertinent to the cross-cultural domain. Even though it is impossible to retrieve data relevant to distribution of nationality of students in secondary schools, it still safe to assume that in a significant number of secondary schools, students with Greek citizenship will not be the dominant population. This assumption is based on the fact that a part of the recent immigration flows from the eastern borders has finally settled in Greece. Hence, since, our research population becomes slightly smaller, the matched sample will account for a percentage that is greater than $2.2 \%$ out of the research population.

The sampling method that has been followed is ratified random sampling. The research population has been sorted in three different categories based on the financial status of the students. This selection has been made on the one hand in order to avoid overly or reduced representation of students with a certain financial status and on the other hand in order to perform comparisons among the different categories. The three different categories chosen are High, Medium and Low economic status.

In order to distribute the schools in one of the aforementioned categories the price per square meter zone index (p/smzi) assumption has been considered. Attica prefecture real estate is categorized in zones of different price per square meter. It is safe enough to assume that secondary schools that are established in zones with high price per square meter zone index will attract students who come from wealthier families and vice-versa. Schools established in areas where the $\mathrm{p} / \mathrm{smzi}$ (let $\mathrm{z}$ be the $\mathrm{p} / \mathrm{smzi}$ ) is $\mathrm{z}<=1.000 €$ per s.m. are classified as Low Economic Status, schools established in areas where the $\mathrm{p} / \mathrm{smzi}$ is $1.000 € /$ per s.m $<\mathrm{z}<2,000 € /$ per s.m are classified as Medium Economic Status and schools established in areas where the $\mathrm{p} / \mathrm{smzi}$ is $\mathrm{z} \geq 2.000 € / \tau$. $\mu$. are classified as High Economic Status.

The data collection has been performed through taking photos of the visual representations in the school areas. The time of photographing took place between 14.00 and 18:00, in order to ensure similar light conditions. Minimum interference with the students has been of primary importance throughout this process. The total number of photos has been taken between October 2018 and April 2019, in order to keep a common timeframe. JPEG has been chosen as the common photograph files format to avoid interchangeability problems as well as processing and storage issues. Finally, in order maintain the commonality of the premises that need to be included, it has been decided to take photos from all the outdoor areas, all indoor areas and three classrooms per school. 


\section{Results}

All the visual representations (a total of 1,192 photos) collected have been qualitatively classified in 16 major categories that are summarized in Table 1 . The dominant category for all three financial levels is art, accounting for $27.7 \%$ of occurrences in the total sample. We need to note that a considerable number of visual representations (12.8\%) fall in the category "Non-specific content". In this category, we have included all images of both indoor and outdoor school areas with no specific message.

Table 1. Categories of visual representations

\begin{tabular}{|c|c|}
\hline$\#$ & CATEGORY \\
\hline 1 & Courses \\
\hline 2 & Sports \\
\hline 3 & Politics \\
\hline 4 & Art \\
\hline 5 & Music \\
\hline 6 & Religion \\
\hline 7 & Romanticism \\
\hline 8 & Non Specific Content \\
\hline 9 & Racial Insults \\
\hline 10 & General Insults \\
\hline 11 & Sexual Insults \\
\hline 12 & Trophies \\
\hline 13 & Humor \\
\hline 14 & Signs \\
\hline 15 & Names \\
\hline 16 & Various \\
\hline
\end{tabular}

Moreover, the visual representations have been classified in three major categories based on the existence or not of text: "text only", "images \& text", and "images only". 27.18\% of the visual representations of the sample have been identified as "text only". This category has been further subdivided in official and unofficial visual representations, namely in those which are approved by the school administration and in those that have been "informally" created.

In the Low Economic Status, a total of 15 unofficial text only visual representations have been identified, whereas in the Medium and High economic statuses the respective scores are 77 and 9. The relative frequencies of the text only visual representations per subcategory (official versus unofficial) for all three financial levels is illustrated in the graph of Figure 1.

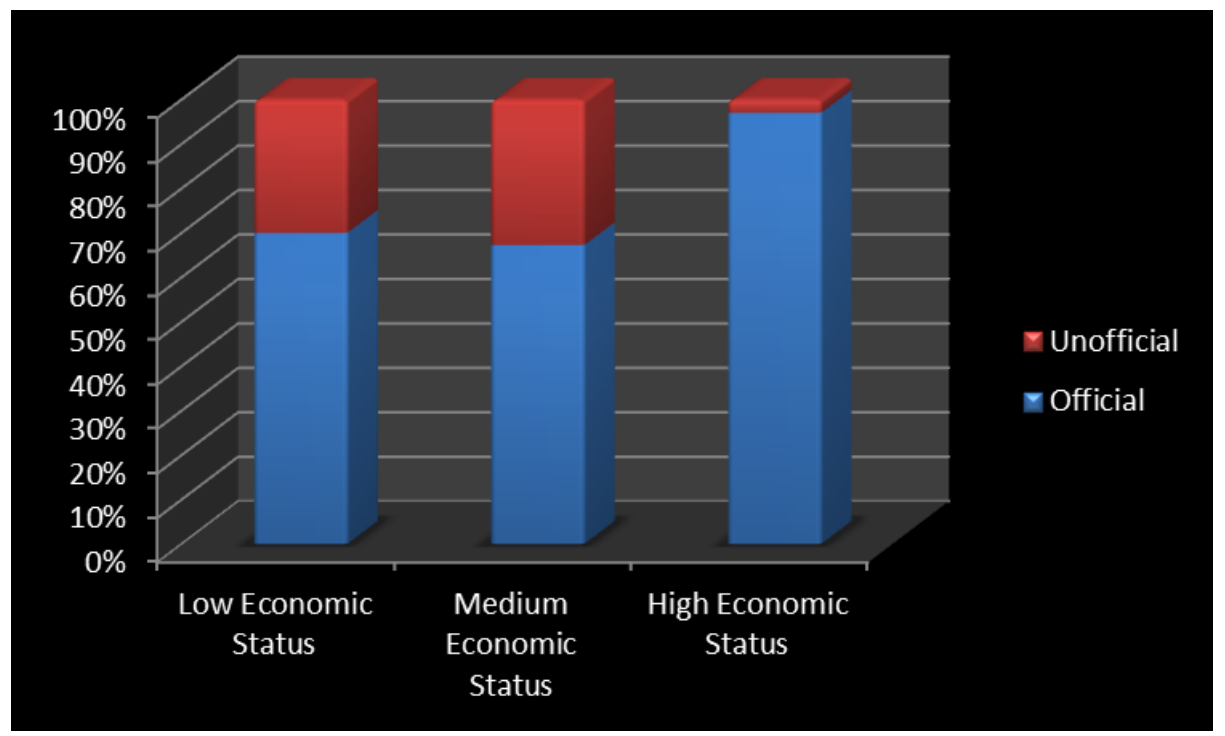

Figure 1. Relative Frequencies for Text Only Subcategories (official-unofficial). 
Furthermore, we have noticed a considerable difference in hate speech content in school of Medium Economic Status regarding the unofficial visual representations of the text only category. More specifically, in Medium Economic status a total of 150 representations have been identified, whereas in schools with Low and High Economic statuses the respective scores are 12 and 56.

\section{Discussion}

Drawing on the results of the survey we could argue that schools of low socioeconomic background createdvery few messages and were exposed to messages mainly regarding school values and rules. In Schools of medium socioeconomic rank, however, there were more messages either created by students or had students; comments on them. In schools of high economic rank the messages students created were few, however, they were exposed to a variety of positive messages evolving around the opportunities the school provides for excitement, enjoyment; thereby playing a significant role in reinforcing/promoting desirable norms and establishing ideals (Image 1). Another finding, was that in high income schools the community, especially the parents association were allowed and given space to put messages inside the school, usually of informative nature about forthcoming activities.

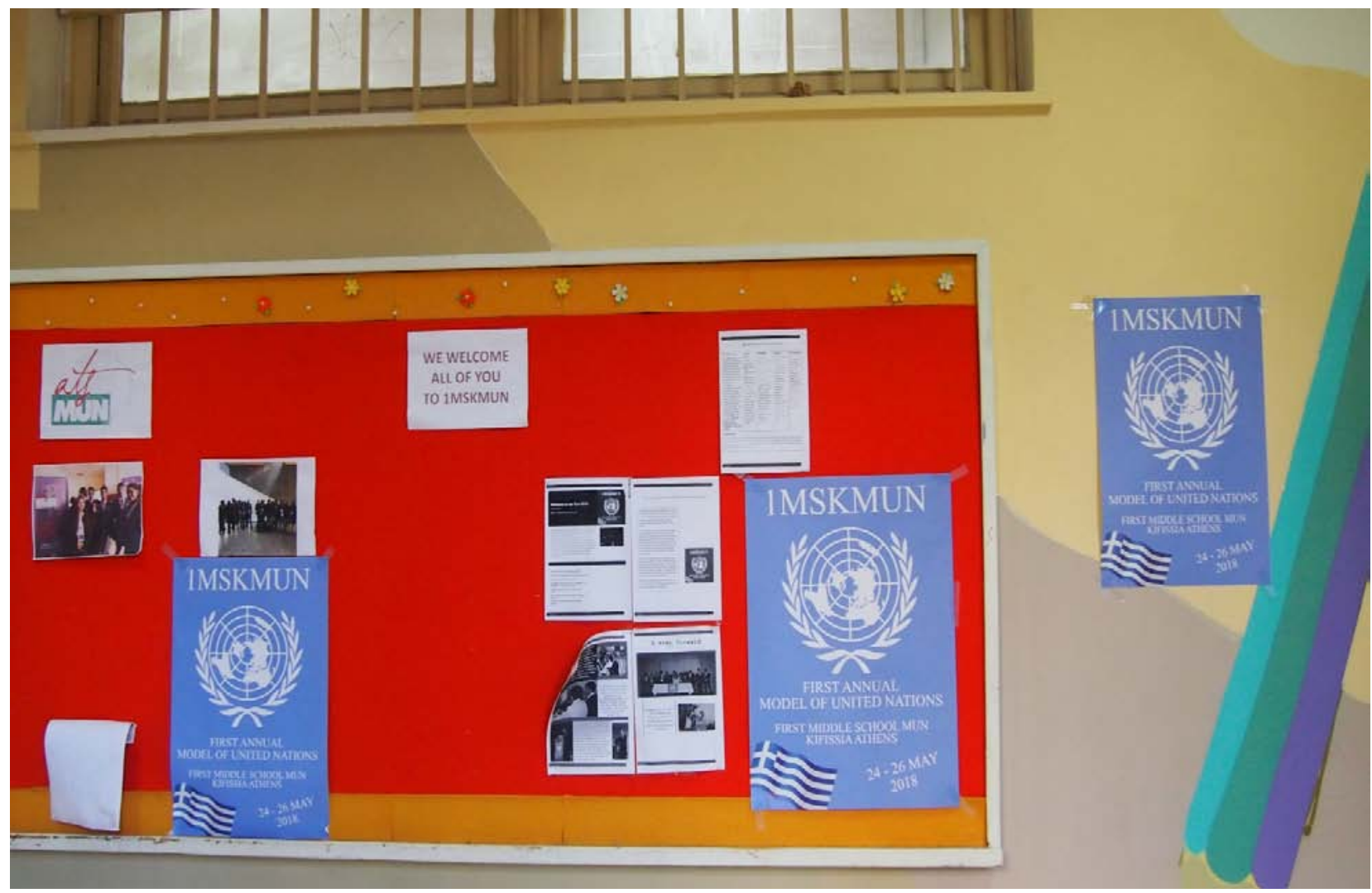

\section{Image 1.}

At this point of our paper, we feel the need to draw our readers' attention to the fact that hate speech was found in schools of medium economic rank both outside and inside the school premises. Also, these messages where are produced mainly by students. On students' desks, chairs around the school walls and even on the schools entrance there were messages calling students not to tolerate racism, xenophobia, different sexual orientation, etc. through violent physical acts (Image 2 and Image 3). When we asked the teachers and headmasters about the existence of such messages they articulated, that although they felt that such messages are likely to trigger physical violence and may lead students to a slippery slope, they maintained that there are no formal rules that regulate or ban such language and vocabularies at schools. This lack of restrictions against the use of offensive language and confrontational speech that insulted the dignity of minority groups is the result of an issue hardly new. There have been attempts to regulate demeaning and vicious expression and offensive language at schools however, these attempts were have failed to start a debate of what constitutes hate speech, what ideas are allowed to be expressed within a school. 


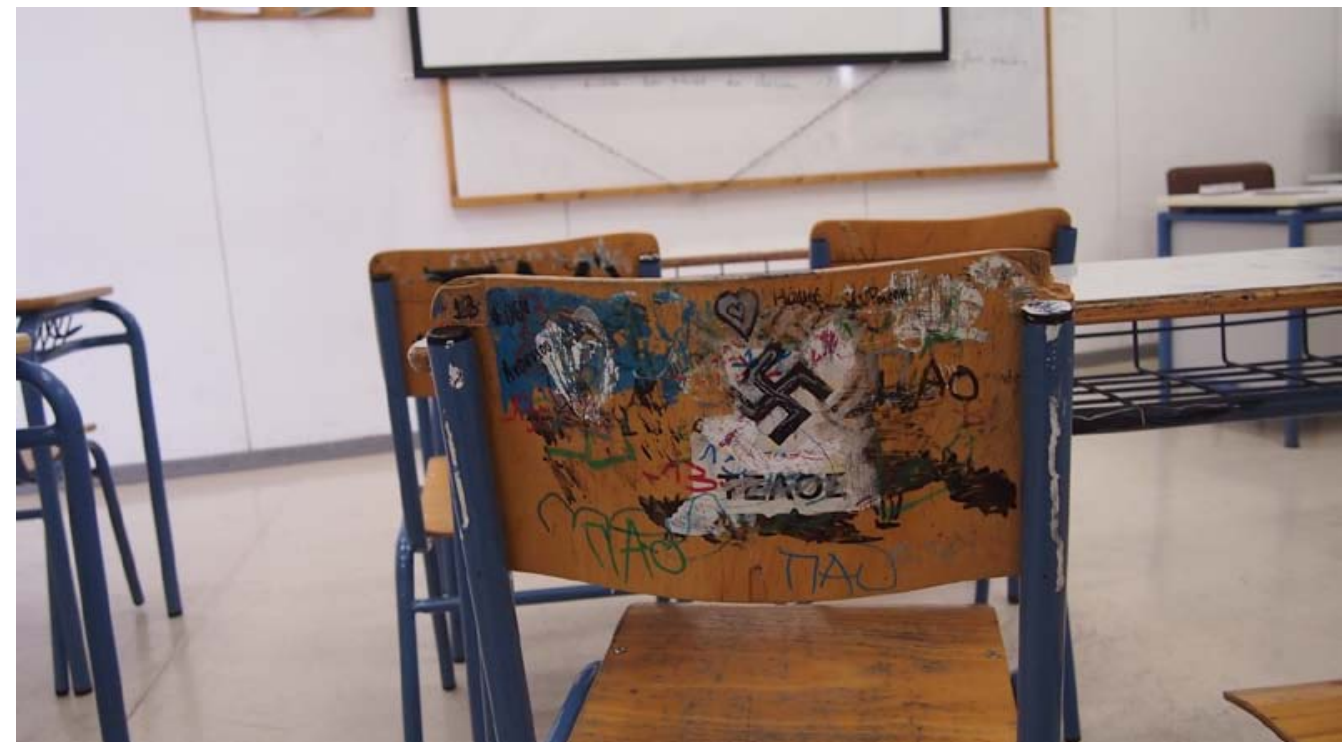

Image 2.

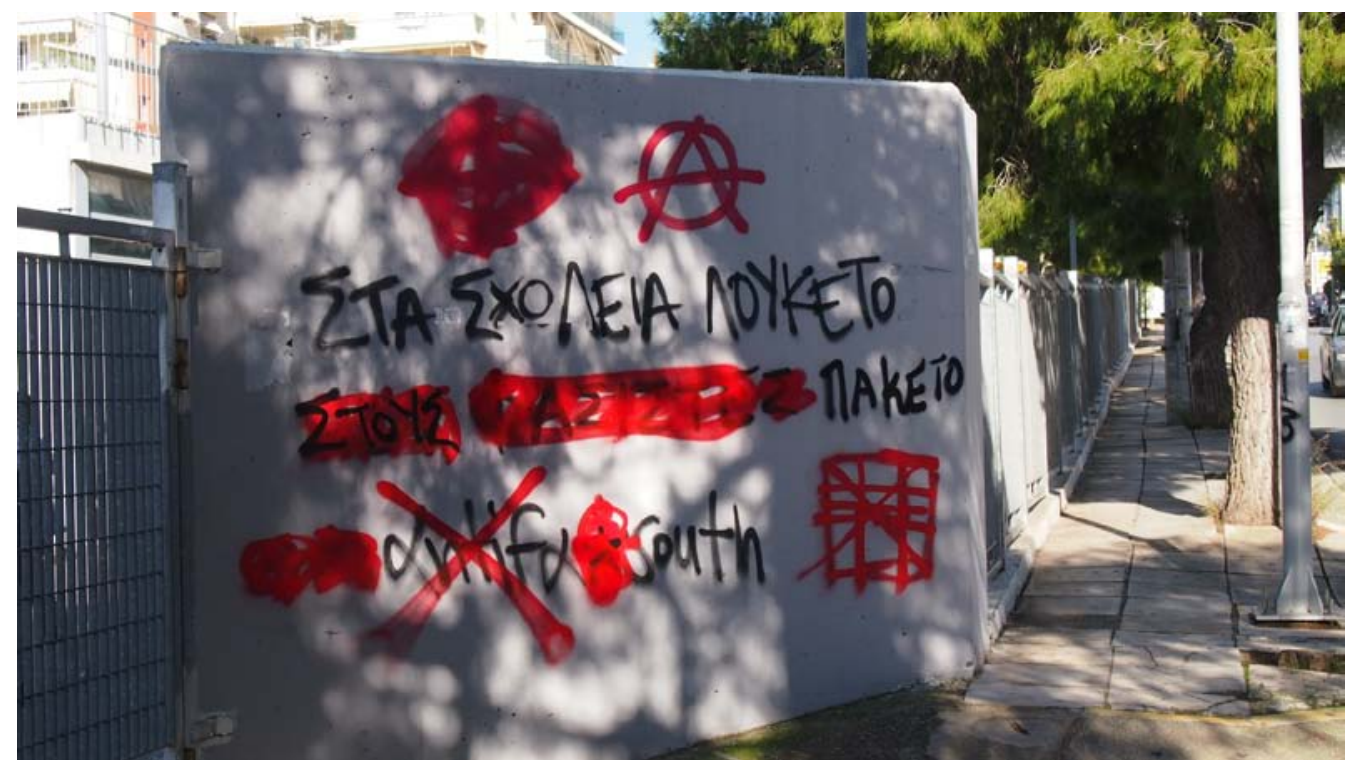

Image 3.

These concerns were so difficult to be met because of this issue includes both abstract and philosophical values as well as concrete and practical ones $(\mathrm{Xu}, 2010)$. It has been put forward that restricting speech especially in controlled environments can give rise to unrest and even foster and atmosphere of tension and friction (Nockleby, 2000). Other researchers express the worry that even if certain terms or epithets are identified as 'unlawful' new ones will be created/used almost immediately resulting to a non workable solution to hate speech in schools (Massaro, 1991). Others even articulated that such restrictions could even make hate speech more attractive to rebellious teenagers.

There are also voices that insist (Banks, 2010), that neither a government nor a Ministry should censor nor hinder speech on the basis of the opinion expressed, no matter how offensive. They maintain that slurs are words, and as such have ideational content, however vulgar and confrontational (Harris, 2009). As a result, none has the right block such expressions unless and until a fight or other serious disruption and physical act is imminent.

Having observed this increase of hate speech in schools as well as we would like to point that although the issue of regulating speech in schools can be a multidimensional issue to tackle, our research results shows that it is an issue that needs to be addressed and further research must be conducted. Students express hate and are exposed to hate messages 
to an alarming extend. Although, we could not explore and identify the extent to which these messages actually affect students' thinking. We feel we must indicate the increasing percentage of hate speech in school environments. Finally, we strongly argue for further research on students messages since these marginalized pupils opinions that are of most value in stimulating institutional change; because they are the most strongly subject to the taken for granted and unquestioned by those who are more powerful. Such research is not without obstacles. There were many hurdles that needed to be overcome for our research to be feasible. Obtaining consent to enter the school was time consuming and involved a lot of bureaucracy.

Another major challenge this project faced was securing schools' participation. Even with the ministry's permission most schools were reluctant to participate and posed several hurdles on the process. Particularly most school principal wanted to check the photos taken and usually insisted on deleting photos that contained messages/signs that could diminished authority or could portray the school as neglected by the principal. Faced with a method not commonly used and not anticipated the principal expressed considerable anxiety and skepticism. The teachers' and principal's reactions reflect wider anxieties about camera-use at school. A number of high profile media cases involving students taking photos on mobile phones and distributing them via the internet have heightened fears about this issue (Allen, 2009; Dennis, 1999). Some of the schools enforce strict rules around camera phones and punish students for inappropriate use. When cameras were routinely perceived as problematic their research use was perceived too perilous and as undermining school authority. Anxiety about cameras appears to invoke a 'double standard' with photographs viewed potentially more exposing and dangerous than written text. Emmison and Smith (2000) reveal this point in their discussion of authors' and editors' reluctance to include photographs in published works: What is ironic, we suggest, is that whilst photographs are often deemed to be unacceptable by authors and editors, textually explicit descriptions of morally suspect materials are considered less so. Such a 'double standard' tell us quite a lot about the relationship of our society to the image as opposed to the text. Whilst texts are associated with reason and higher mental faculties, images are seen as subversive, dangerous and visceral (Emmison \& Smith, 2000). This unease related to the school being identifiable even with the use of a code.

The research was only allowed to proceed on our guarantee measures would be taken to prevent the school's identification. School-based research can also be hindered, by congested timetabling also hampers accommodating 'an extra' like research, when academic pursuits take precedence. In addition, the need to negotiate alterations to ethical approval. Although time-intensive, acting on teachers' suggestions was a means signaling their concerns were valued. Key to participation in schools was the ministry's consent and supportive teachers who considered the research beneficial to students and helped quell senior management's anxieties. Securing school participation was subsequently a challenge as the research was constituted as 'too risky' by principals anxious to avoid unwanted publicity.

During our research as aforementioned issues of gender, sexuality, minority groups, hate speech emerged since, visual images/messages regarding gender and sexuality were the second most commonly produced, by students. However, researching issues of sex, hate, gender etc. issues in schools is challenging because it asks questions about an issue which is socially constituted as 'private', 'embarrassing', 'non relevant to educational goals" "political” and subsequently 'problematic'.

Finally, we feel that messages in a school can act as a contact zone, where teachers and students can come together, if not on equal terms, nevertheless in a place were communication and apprehension of each other views is possible. The images and texts can foreground different perspectives which provide different questions and alternative to the dominant accounts of schooling. None of this however is possible if visuals are not "seen" and explored in the educational process.

\section{References}

Allen, L. (2009). Caught in the act: Ethics committee review and researching the sexual culture of schools. Qualitative Research, 9/4: $1-16$.

Argyris, C. (1958). Personality and Organisation: The Conflict Between the System and the Individual. New York: Harper and Row.

Banks, J. (2010). Regulating hate speech online. International Review of Law, Computers \& Technology, 24: 3, 233-239. DOI: $10.1080 / 13600869.2010 .522323$.

Bragg, S. (2007). Student Voice and Governmentality: The production of enterprising subjects? Discourse: Studies in the Cultural Politics of Education 28/3: 343-358. DOI: 10.1080/01596300701458905.

Burke, C. and I. Grosvenor. (2003). The School I'd Like: Children and Young People's Reflections on an Education for the $21^{\text {st }}$ Century. Routledge.

Cook-Sather, A. (2014). The trajectory of student voice in educational research. New Zealand Journal of Educational Studies 49/2: 
131-148.

Cremin, H. and B. Slatter. (2004). Is it possible to access the voice of pre-schoolchildren? Results of a research project in a pre-school setting. Educational Studies, 30/4: 457-470. DOI: 10.1080/0305569042000310363.

Denis, M. and S. M. Kosslyn. (1999). Visual mental imagery and visual perception: Structural equivalence revealed by scanning processes. Memory and Cognition, 36/4: 849-862.

Education Act. (2002). https://www.legislation.gov.uk/ukpga/2002/32/contents.

Emmison, M. and P. Smith. (2000). Researching the Visual: Images, Objects, Contexts and Interactions in Social and Cultural Inquiry. London: Sage.

Fielding, M. (2004). New wave student voice and renewal of civic society. London Review of Education, 2/3: 197-217. DOI: $10.1080 / 1474846042000302834$.

Flutter, J. and J. Rudduck. (2004). Consulting Pupils: What's in It for Schools. Routledge.

Halliday, M. A. K. (2006). Linguistic Studies of Text and Discourse. Continuum.

Harris, C., J. Rowbotham, and K. Stevenson. (2009). Truth, Law and Hate in the Virtual Marketplace of Ideas: Perspectives on the Regulation of Internet Content. Information and Communications Technology and Law, 18/2: 155-184.

Hill, M. (2006). Children's voices on ways of having a voice: children and young people's perspectives on methods used in research and consultation. Childhood, 13/1: 69-89. DOI: 10.1177/0907568206059972.

Holmes, J. and N. Wilson. (2017). An Introduction to Sociolinguistics. Routledge.

James, A., C. Jenks, and A. Prout. (1998). Theorizing Childhood, Cambridge: Polity Press.

Jenkins, E. W. (2006). The student voice and school science education. Studies in Science Education, 42/1: 49-88. DOI: $10.1080 / 03057260608560220$.

Jewitt, C. and R. Oyama. (2001). Visual meaning: A socialsemiotic approach. In Handbook of Visual analysis, edited by Theo van Leeuwen and Carey Jewitt. London: Sage.

Kalantzis, M. and B. Cope. (2008). New Learning: Elements of a Science of Education. Cambridge University Press.

Lewin, K. R., R. Lippitt, and R. K. White. (1939). Patterns of aggressive behaviour in three social climates. Journal of Social Psychology, 10: 271-99.

Lodge, C. (2005). From hearing voices to engaging in dialogue: Problematising student participation in school improvement. Journal of Educational Change, 6/2: 125-146. DOI: 10.1007/s10833-005-1299-3.

Mascolo, M. (2009). Beyond Student-Centered and Teacher-Centered Pedagogy: Teaching and Learning as Guided Participation Teaching and Learning as Guided Participation. International Journal of Teaching and Learning in Higher Education, 23/2: pp. 92-97.

Massaro, T. M. (1991). Equality and freedom of expression. William and Mary Law Review, 32/3: 211-265.

Mortimore, P. (1979). The study of secondary schools: A researcher's reply' in The Rutter Research: Perspectives 1 . University of Exeter.

Netsafe. (2005). The text generation mobile phones and New Zealand youth: A report of results from the internet. www.netsafe.org.nz/Doc_Library/publications/text_generation_v2.pdf (accessed July 6, 2020). safety group's survey of teenage mobile phone use.

Nockleby, J. T. (2000). 'Hate speech' in (2nd ed., edited Levy, L. W., K. L. Karst et al. (eds.): Encyclopedia of the American Constitution. $\quad 2^{\text {nd }}$ ed., Macmillan, 1277-1279, retrieved February 5, 21, from http://www.jiffynotes.com/a study_guides/book_notes/eamc_03/eamc_03_01193.html.

Prosser, Jon. (2007). Visual methods and the visual culture of schools. Visual Studies, 22(1): 13-30.

Smyth, J. (2006). When students have power: Student engagement, student voice, and the possibilities for school reform around dropping out of school. International Journal of Leadership in Education, 9/4: 285-298. DOI: 10.1080/13603120600894232.

United Nations Convention on the Rights of the Child. (1989). UN General Assembly Resolution 44/25. http://www.un.org/documents/ga/res/44/a44r025html.

$\mathrm{Xu}, \mathrm{Z}$. and S. Zu. (2010). Filtering offensive language in on-line Communities using grammatical relations. $7^{\text {th }}$ Annual Collaboration, Electronic Messaging, Anti-Abuse and Spam Conference, CEAS 2010. 